\title{
Movement-Related Cortical Stimulation Can Induce Human Motor Plasticity
}

\author{
Mohamed Nasreldin Thabit, ${ }^{1,2}$ Yoshino Ueki, ${ }^{1}$ Satoko Koganemaru, ${ }^{1}$ Gharib Fawi, ${ }^{2}$ Hidenao Fukuyama, ${ }^{1}$ \\ and Tatsuya Mima ${ }^{1}$ \\ ${ }^{1}$ Human Brain Research Center, Kyoto University Graduate School of Medicine, Kyoto 606-8507, Japan, and 2Department of Neurology, Faculty of \\ Medicine, Sohag University, Sohag 82524, Egypt
}

Repeated paired associative stimulation combining peripheral nerve stimulation and transcranial magnetic stimulation (TMS) of the primary motor cortex (M1) can produce human motor plasticity. However, previous studies used paired artificial stimuli, so that it is not known whether repetitive natural M1 activity associated with TMS can induce plasticity or not. To test this hypothesis, we developed a movement-related cortical stimulation (MRCS) protocol, in which the left M1 was stimulated by TMS at specific timing with respect to the mean expected reaction time (RT) of voluntary movement during a simple reaction time task using the right abductor pollicis brevis (APB) muscle. Seventeen normal volunteers were subjected to repeated MRCS intervention ( $0.2 \mathrm{~Hz}, 240$ pairs). Motor function was assessed before and after MRCS. When TMS was given $50 \mathrm{~ms}$ before the RT of movement [MRCS(-50)], motor-evoked potential (MEP) amplitude of the right APB, but not other muscles, increased for up to 15 min post-MRCS. The RT of the right APB was also shortened. However, spinal excitability measured by F-wave did not change. When TMS was given $100 \mathrm{~ms}$ after the RT [MRCS(+100)], MEP amplitude was decreased. These findings show that this new MRCS protocol can produce timing-dependent motor associative plasticity, which may be clinically useful.

\section{Introduction}

Synaptic plasticity refers to an activity-dependent modification of synaptic strength (Citri and Malenka, 2008). Hebb's postulate of synaptic modification by correlated activity has become a cornerstone in our understanding of activity-dependent neural plasticity (Hebb, 1949), and was linked to the processes of long-term potentiation (LTP) and/or inhibition (LTD) (Bliss and Lomo, 1973). Long-term potentiation can be induced by use of pairing protocols (associative or Hebbian LTP), which imply synchronous activation of two inputs to a neuron, or synchronous presynaptic and postsynaptic depolarization. Together, LTP and LTD allow activity-dependent modification of synaptic strength, thus serving as promising candidates for the synaptic basis of learning and memory (Martin et al., 2000).

Stefan and others succeeded to induce plasticity in the human primary motor cortex (M1) by pairing low-frequency peripheral nerve stimulation with transcranial magnetic stimulation (TMS) over the contralateral M1. This paired associative stimulation (PAS), rapidly induces a long lasting, reversible, and somatotopically specific increase in the cortical excitability, which may be related to the associative LTP (Stefan et al., 2000).

Received April 10, 2010; revised July 6, 2010; accepted July 10, 2010.

This study is partly supported by the Strategic Research Program for Brain Sciences to T.M. from the Ministry of Education, Culture, Sports, Science and Technology of Japan, and Grant-in-Aid for Scientific Research (C) 21613003 to T.M. from Japan Society for the Promotion of Science.

Correspondence should be addressed to Dr. Tatsuya Mima, Department of Brain Pathophysiology, Human Brain Research Center, Kyoto University Graduate School of Medicine, Shogoin Kawahara-cho 54, Sakyo-ku, Kyoto 6068507, Japan. E-mail: mima@kuhp.kyoto-u.ac.jp.

DOI:10.1523/JNEUROSCI.1829-10.2010

Copyright $\odot 2010$ the authors $\quad 0270-6474 / 10 / 3011529-08 \$ 15.00 / 0$
The associative LTP in animal models can be induced when an action potential of the postsynaptic neuron was preceded by the EPSP induced by another input. If the order of stimulation was reversed, LTD of that input is induced (Allen and Tsukahara, 1974; Markram et al., 1997; Bi and Poo, 1998; Debanne et al., 1998; Feldman, 2000). This form of associative plasticity is governed by a strict temporally asymmetric rule. Similarly in human, following PAS, when the median nerve stimulation preceded TMS pulse by $25 \mathrm{~ms}$, M1 excitability increased, whereas PAS with ISI of $10 \mathrm{~ms}$ led to its depression (Wolters et al., 2003).

In previous forms of PAS, the peripheral electrical stimulation induces activity in M1 through thalamocortical "vertical" and/or corticocortical fibers from the somatosensory cortex (Wolters et al., 2005). However, it has been rarely investigated whether other types of afferent input to M1 combined with TMS can produce similar associative LTP-like effects (Koganemaru et al., 2009; Rizzo et al., 2009) or not. One recent animal study showed that the repetitive activation of the artificial connection between M1 neurons via implantable electronic circuits can produce longterm plasticity (Jackson et al., 2006). If associative stimulation is a general principle for human neural plasticity, it is possible that natural physiological activation of M1 during the reaction time task synchronized with TMS can also produce associative LTP/ LTD-like plasticity.

Instead of pairing a peripheral nerve stimulation (Stefan et al., 2000, 2002; Wolters et al., 2003) or contralateral M1 stimulation (Koganemaru et al., 2009; Rizzo et al., 2009) with TMS, we consistently paired voluntary thumb abduction movement with TMS over M1; movement-related cortical stimulation (MRCS). As a paired stimulation which was repeated in MRCS, we applied 
TMS over M1, before or after the mean RT of thumb movements during the overlearned reaction time task. We hypothesized that MRCS combining TMS with endogenous movement-related activity in M1 can induce timing-dependent plasticity in motor function.

\section{Materials and Methods}

Subjects. Experiments were performed on 17 healthy volunteers ( 9 males, and 8 females) aged $19-43$ years (29.5 \pm 6 years). All subjects were right handed as determined by Oldfield handedness inventory (Oldfield, 1971). None of the subjects had a history of neurological or psychiatric disorders or was under drug treatment during experiments. All subjects gave written informed consent before experiments. The protocol was approved by the Ethics Committee of Kyoto University Graduate School of Medicine.

Recordings. Each subject was seated comfortably on an armchair with his or her arms placed on the armrest with the hands facing upward. Surface electromyogram (EMG) was recorded from the abductor pollicis brevis (APB) and abductor digiti minimi (ADM) muscles on both sides (experiment 1) or on the right side (experiments 2, and 3), using pairs of silver electrodes. The EMG signals were amplified, bandpass filtered $(5-2000 \mathrm{~Hz})$, digitized at a rate of $10 \mathrm{kHz}$ and stored for offline analysis. The subjects were asked to keep relaxation throughout the experiments with the aid of visual feedback from the EMG monitor.

TMS. TMS was given using a figure-of-eight coil ( $9 \mathrm{~cm}$ for the outer diameter) connected to a Magstim 200 stimulator (Magstim Company). The optimal motor point for eliciting the best MEP (hot spots) for APB muscle was established by a suprathreshold stimulus over the $\mathrm{M} 1$ contralateral to the target muscle with the coil held $\sim 45^{\circ}$ to the midsagittal line (approximately perpendicular to the central sulcus). The optimal position was marked on the scalp by a soft tip pen to ensure identical placement of the coil throughout the experiment. The direction of the induced current was from posterior to anterior.

TMS measurements. The resting motor thresholds (rMT) for relaxed APB muscle(s) were determined to the nearest $1 \%$ of the stimulator output and defined as the lowest stimulus intensity required for eliciting MEP with peak to peak amplitude $>50 \mu \mathrm{V}$ in at least 5 of 10 trials (Rossini et al., 1994). The active motor threshold (aMT) was recorded as the minimum intensity at which MEPs with an amplitude of $\sim 200 \mu \mathrm{V}$ can be distinguished from the background activity in 50\% of trials (Rothwell et al., 1999).

For the evaluation of the corticospinal excitability, we measured the peak-to-peak MEP amplitudes of the right and left APB and ADM muscles for 20 trials and the averages were taken. The intensity of the test stimulus was adjusted to produce MEP of $\sim 0.5-1 \mathrm{mV}$ from the relaxed APB muscle before MRCS $\left(\mathrm{SI}_{1 \mathrm{mV}}\right)$.

For silent period (SP) recording, the stimulation intensity was adjusted to be $120 \%$ of the rMT of the right APB before MRCS. The SP was assessed during the isometric contraction of the right $\mathrm{APB}$ at $\sim 15 \%$ of the maximum force. Its duration was taken from the onset of TMS to the return of voluntary EMG activity.

For the measurement of short interval intracortical inhibition (SICI), paired pulse magnetic stimuli were applied over the hot spot of the right APB muscle (Kujirai et al., 1993). The intensity of the conditioning stimulus was adjusted to $95 \%$ of aMT measured before MRCS, and that of the test stimulus was adjusted to $\mathrm{SI}_{1 \mathrm{mV}}$ with an interstimulus interval (ISI) of 3 ms (Ziemann et al., 1996b). For further analysis, the ratio of the conditioned MEP divided by the test MEP was used.
F-wave measurements. Excitability of spinal motor neurons was examined by F-wave (Mercuri et al., 1996). The F-wave at right APB muscle was evoked by supramaximal electrical stimulation of the median nerve at wrist before and after the intervention. Twenty F-waves were recorded and averaged.

Pinch force. Pinch forces of both hands were determined using Jamar pinch gauge (Sammons Preston Inc.). Subjects were instructed to press the handle of the pinch gauge with the maximum power by using the thumb and index fingers.

Simple reaction time task. Subjects were comfortably sitting on an armchair with padded armrests, facing a computer monitor situated at $\sim 100$ $\mathrm{cm}$ before the eyes of subjects. Their forearms were relaxed on top of a small table of adjustable height. They were requested to position their thumb on keyboard buttons in a comfortable position, and instructed to react to a visual cue (the green circle, visual angle: $1.7^{\circ}$ ) that appeared on the computer monitor (ISI $=5 \mathrm{~s}$ ) by pressing the button as rapid as possible after stimulus presentation, by brisk thumb abduction movement. Twenty five trials were measured for each hand separately, and the mean RTs were computed.

MRCS. During the intervention protocol, subjects continuously performed the simple reaction time task (SRT) for $20 \mathrm{~min}($ ISI $=5 \mathrm{~s}$ ) (Fig. 1). The only difference was that subjects performed the thumb abduction without holding the button. After subjects overlearned the SRT, the mean reaction time of movement EMGs $\left(\mathrm{RT}_{\mathrm{emg}}\right)$ for each subject was determined by measuring the time between the onset of the cue and that of the EMG recorded from the right APB (20 trials).

For MRCS, TMS was given at the left M1 in association with the mean estimated $\mathrm{RT}_{\text {emg. }}$. The pairs of TMS and movement were repeated at a rate of $0.2 \mathrm{~Hz}$ for 240 pairs along $20 \mathrm{~min}$. The TMS intensity was $120 \%$ of the rMT of the right APB before the intervention. During the main ex- 
Table 1. Behavioral and electrophysiological changes after $\operatorname{MRCS}(+50)$ and $\operatorname{MRCS}(-50)$ in experiment 1

\begin{tabular}{|c|c|c|c|c|c|c|}
\hline \multirow[b]{2}{*}{ Measures } & \multirow[b]{2}{*}{ Types of MRCS } & \multirow[b]{2}{*}{ Site } & \multicolumn{4}{|l|}{ Time } \\
\hline & & & Pre & Post-0 & Post-15 & Post-30 \\
\hline \multirow[t]{4}{*}{ Pinch force $(\mathrm{kg})$} & \multirow[t]{2}{*}{$\operatorname{MRCS}(-50)$} & Right hand & $3.5 \pm 0.3$ & $3.6 \pm 0.4$ & $3.4 \pm 0.4$ & $3.6 \pm 0.4$ \\
\hline & & Left hand & $3.2 \pm 0.3$ & $3.3 \pm 0.4$ & $3.4 \pm 0.4$ & $3.4 \pm 0.4$ \\
\hline & \multirow[t]{2}{*}{$\operatorname{MRCS}(+50)$} & Right hand & $3.3 \pm 0.5$ & $3.3 \pm 0.4$ & $3.3 \pm 0.4$ & $3.4 \pm 0.5$ \\
\hline & & Left hand & $3.3 \pm 0.4$ & $3.3 \pm 0.4$ & $3.2 \pm 0.4$ & $3.4 \pm 0.4$ \\
\hline \multirow[t]{4}{*}{ Motor evoked potential amplitude ( $\mu \mathrm{V})$} & \multirow[t]{2}{*}{$\operatorname{MRCS}(-50)$} & Right APB & $611 \pm 59$ & $1323 \pm 248^{*}$ & $1113 \pm 149^{*}$ & $714 \pm 66$ \\
\hline & & Right ADM & $633 \pm 170$ & $714 \pm 173$ & $904 \pm 224$ & $842 \pm 227$ \\
\hline & \multirow[t]{2}{*}{$\operatorname{MRCS}(+50)$} & Right APB & $937 \pm 237$ & $848 \pm 159$ & $901 \pm 170$ & $1077 \pm 325$ \\
\hline & & Right ADM & $627 \pm 135$ & $630 \pm 123$ & $562 \pm 142$ & $560 \pm 119$ \\
\hline \multirow[t]{4}{*}{ Resting motor threshold (\%) } & \multirow[t]{2}{*}{$\operatorname{MRCS}(-50)$} & Right APB & $54.2 \pm 3.7$ & $53 \pm 3.9$ & $53 \pm 3.6$ & $52.6 \pm 3.7$ \\
\hline & & Left APB & $60.3 \pm 4.1$ & $59.1 \pm 3.9$ & $60.7 \pm 4.0$ & $60 \pm 4.2$ \\
\hline & \multirow[t]{2}{*}{$\operatorname{MRCS}(+50)$} & Right APB & $55.8 \pm 2.5$ & $55.5 \pm 2.7$ & $53.8 \pm 2.8$ & $54.9 \pm 2.7$ \\
\hline & & Left APB & $54.6 \pm 2.8$ & $56.3 \pm 2.9$ & $55.3 \pm 2.9$ & $54.7 \pm 2.7$ \\
\hline
\end{tabular}

Mean \pm SEM, ${ }^{*} p<0.05$
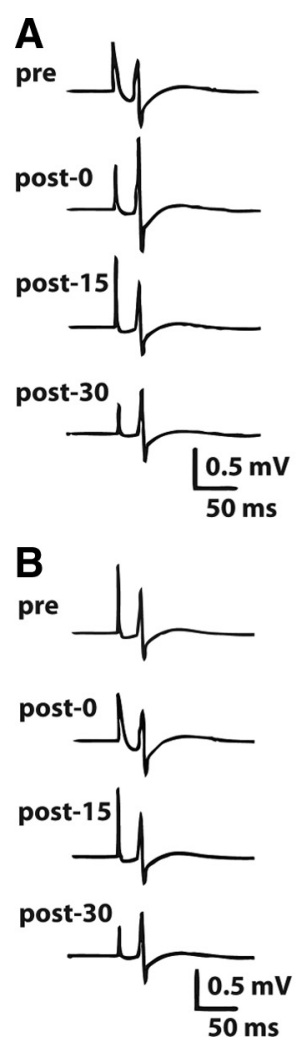

Rt APB $\square$ Rt ADM
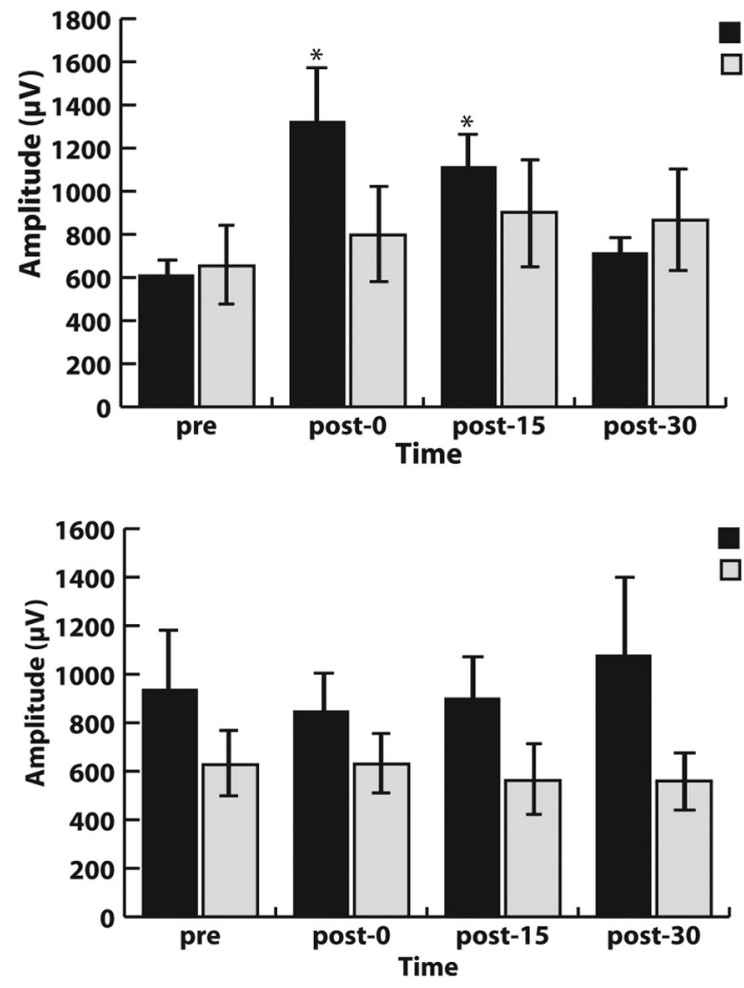

Figure 2. Effect of MRCS( -50$)$ on MEP amplitudes. $A$, EMG traces in one representative subject (left side) and the MEP amplitudes (mean \pm SEM) of the right APB and ADM for pre, post- 0 , post- 15 , and post-30 min of the intervention (right side) were shown. Significant increase was observed only for the right $A P B$ at post -0 and post- 15 conditions. In this and other figures, asterisks represent the significant change $\left(t\right.$ test, $\left.{ }^{*} p<0.05,{ }^{*} p<0.01\right)$. Effect of MRCS(+50) on MEP amplitudes. $\boldsymbol{B}$, The mean EMG traces in one representative subject (left side) and the MEP amplitudes (mean \pm SEM) of the right APB and ADM for pre, post-0, post- 15 , and post- $30 \mathrm{~min}$ of the intervention (right side) were shown. There was no significant change for this intervention.

periment (experiment 1), TMS was given $50 \mathrm{~ms}$ before and after the $\mathrm{RT}_{\text {emg }}[\mathrm{MRCS}(-50)$, and MRCS $(+50)$, respectively]. In preliminary experiments, the SDs of $\mathrm{RT}_{\mathrm{emg}}$ were $20-30 \mathrm{~ms}$. We used $-50 /+50 \mathrm{~ms}$ of time delay to ensure that TMS would be delivered just before/after the estimated onset of APB contraction. MRCS with other timings $(-100,+100$, $+150 \mathrm{~ms}$ ) were also tested (experiment 3 ). Visual monitoring of the voluntary EMG activity was continued to monitor the EMG silence during the experiment, except for the thumb abduction task triggered by the cue.

Experiment 1: $M R C S(-50)$ versus MRCS $(+50)$ and somatotopy. Thirteen subjects participated in $\operatorname{MRCS}(-50)$, and 12 participated in MRCS(+50). Ten subjects participated in both experiments on different days separated by at least 1 week to counteract any crossover effect. We measured the MEP amplitudes of the right and left APB and ADM, rMT for the right and left $\mathrm{APB}$, and pinch powers for both hands, before (pre), immediately (post-0), $15 \mathrm{~min}$ (post-15), and $30 \mathrm{~min}$ (post-30) after the end of MRCS.

Experiment 2: alterations of detailed motor parameters after MRCS(-50). Eight subjects participated in this experiment. In addition to the MEP amplitude, we evaluated the F-wave amplitude, SICI and SP duration of the right APB muscle. The mean RT of the right and left thumb were measured before and after MRCS $(-50)$ (pre, post- 0 , post-15, post-30).

Experiment 3: effects of ISI on MRCS-induced changes. In six subjects, we studied the effect of different ISI $(-100,-50,+50,+100$, and $+150 \mathrm{~ms}$ ) on the MRCS-induced changes of MEP amplitudes. We measured the MEP amplitudes of the right $\mathrm{APB}$ and $\mathrm{ADM}$ before and after MRCS (pre, post- 0 , post- 15 , and post- 30 ). The order of experiments for different ISI was randomized across subjects. At least a period of 1 week has elapsed between experiments in each subject to counteract any crossover effect.

Data analysis. For statistical analysis, repeatedmeasures ANOVA was used. The factors tested in each experiment are given in more details in the results. The Greenhouse-Geisser method was used for adjustment of sphericity if needed. Two-tailed paired $t$ test with Bonferroni correction was used for post hoc analysis. Effects were considered significant if $p<0.05$. Data are presented as mean \pm SEM.

\section{Results}

The mean $\mathrm{RT}_{\mathrm{emg}} \pm \mathrm{SD}$ was $162.9 \pm 16.4 \mathrm{~ms}$ $(n=17)$. The mean \pm SD of rMT before MRCS was $54.2 \pm 10.9$ and $58.5 \pm 11.6 \%$ for the right and left APB, respectively ( $n=$ 17 and 13). The mean \pm SD of $\mathrm{SI}_{1 \mathrm{mV}}$ was $68.3 \pm 14.9$ and $71.5 \pm$ $13.6 \%$ for the right and left $\mathrm{APB}$, respectively $(n=17$ and 13$)$.

\section{Experiment 1}

The means \pm SEM of this experiment's data are presented in Table 1, which showed the significant increase of MEP amplitudes only after $\operatorname{MRCS}(-50)$. For both $\operatorname{MRCS}(-50)$ and MRCS(+50), repeated-measures ANOVA for pinch force with time (pre, post-0, post-15, post-30) and side (right, left) showed no significant effects of time or time $\times$ side. For MRCS $(-50)$, 
Table 2. Behavioral and electrophysiological changes of the right APB after MRCS(-50) in experiment 2

\begin{tabular}{lllll}
\hline \multirow{2}{*}{ Measures } & Time & & \\
\cline { 2 - 5 } & Pre & Post-0 & Post-15 & $220 \pm 9^{*}$ \\
RT (ms) & $245 \pm 10$ & $218 \pm 10^{*}$ & $944 \pm 159$ & $234 \pm 11$ \\
Motor evoked potential amplitude $(\mu \mathrm{V})$ & $551 \pm 69$ & $944 \pm 152^{*}$ & $614 \pm 103$ \\
Short-interval intracortical inhibition $($ ratio) & $0.35 \pm 0.04$ & $0.45 \pm 0.04$ & $0.48 \pm 0.07$ & $0.4 \pm 0.04$ \\
Silent period duration $(\mathrm{ms})$ & $180 \pm 9$ & $206 \pm 7^{*}$ & $34 \pm 8^{*}$ & $348 \pm 32$ \\
F-wave amplitude $(\mu \mathrm{V})$ & $347 \pm 62$ & $343 \pm 58$ & $396 \pm 58$ \\
\hline
\end{tabular}

Mean \pm SEM, ${ }^{*} p<0.05$.

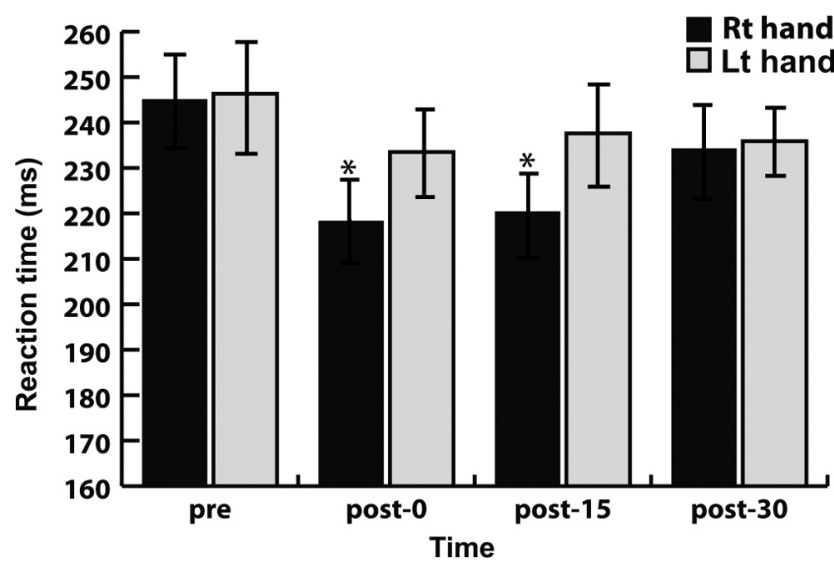

Figure 3. Effect of $\operatorname{MRCS}(-50)$ on simple reaction time. The mean reaction times in both right and left hands for pre, post- 0 , post- 15 , and post- 30 conditions were shown. The significant shortening of the reaction time was observed for post -0 and post- 15 conditions.

two-way repeated-measures ANOVA for MEP amplitude of the right $\mathrm{APB}$ and $\mathrm{ADM}$ with time and muscle as the within-subject variables revealed significant main effect of time $(F=7.602, p=$ $0.005)$, and time $\times$ muscle interaction $(F=6.438, p=0.009)$. Post hoc analysis for each time point revealed significant effects for pre versus post 0 ( $p=0.048)$, and pre versus post- $15(p=0.012)$ in the right $\mathrm{APB}$ (Fig. $2 A$ ). For the right $\mathrm{ADM}$, there was no significant effect. For the left hand, two-way repeated-measures ANOVA showed no significant effect for time and time $\times$ muscle. However, for MRCS $(+50)$, two-way repeated-measures ANOVA with time and muscle as the within-subject variables revealed no significant main effect of time and time $\times$ muscle interaction for both right and left hands. (Fig. 2 B). For rMT, repeated-measures ANOVA showed insignificant effect of time for the right and left APB muscles for $\operatorname{MRCS}(-50)$ and MRCS $(+50)$.

\section{Experiment 2}

Since the pinch force measurement in experiment 1 showed insignificant change, we measured the RT during SRT in addition to detailed electrophysiological measures and found the increase of MEP amplitude and SP duration as well as the shortening of RT. The means \pm SEM of the data of this experiment are presented in Table 2.

The mean \pm SD of TMS intensity used for recording the SP was $73.5 \pm 16.5 \%(n=8)$. The mean \pm SD of aMT was $42.8 \pm 9.7 \%$ and for $\mathrm{SI}_{1 \mathrm{mV}}$ was $68.8 \pm 15.7 \%$ of maximum stimulator output.

Repeated-measures ANOVA with time as the within-subject variable for RT of the right hand was significant $(F=8.816, p=$ 0.001). Post hoc $t$ test revealed significant decrease of RT during post -0 and post -15 conditions ( $p=0.033$ and 0.03 , respectively, Fig. 3). However, for the left hand, it was insignificant (the mean RT was $246 \pm 13,234 \pm 11,238 \pm 12$, and $236 \pm 9 \mathrm{~ms}$ for pre, post- 0 , post- 15 and post- 30 conditions).

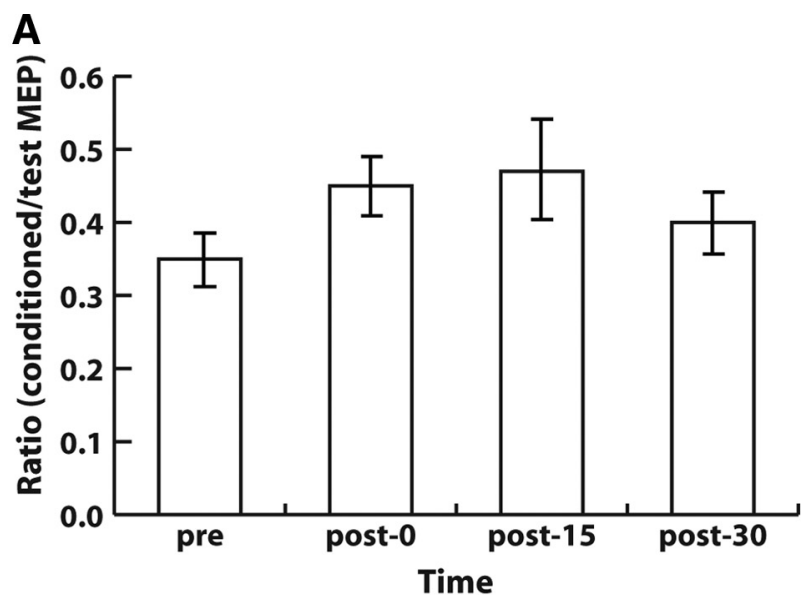

B

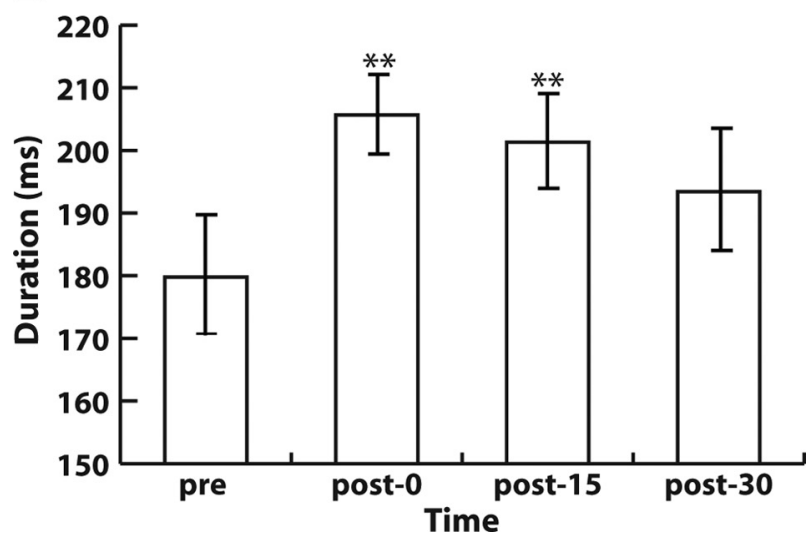

Figure 4. $A, B$, Effect of $\operatorname{MRCS}(-50)$ on the cortical inhibitory system measured by short interval intracortical inhibition $(\boldsymbol{A})$ and silent period $(\boldsymbol{B})$. The mean intracortical inhibition (conditioned/test MEP ratio) in the right APB measured for pre, post -0 , post- 15 , and post -30 conditions showed no significant difference. The mean duration of SP in the right APB for post-0, and post- 15 conditions showed the significant increase after intervention.

Regarding the mean MEP amplitude for the right APB, repeated-measures ANOVA showed the significant effect of time $(F=6.087 ; p=0.004)$. Post hoc $t$ test showed the increase of MEP amplitudes for post-0 compared with pre condition ( $p=0.027)$.

The change in SICI was insignificant after intervention (Fig. $4 A$ ). However repeated-measures ANOVA for the durations of SP of the right APB showed significant effect of time $(F=15.968$, $p<0.001$, Fig. 4 B). Post hoc $t$ test revealed significantly longer SP duration for post- 0 and post- 15 compared with pre condition ( $p=0.003$ and 0.003 , respectively). The mean F-wave amplitudes recorded from the right APB were insignificant (Fig. 5).

\section{Experiment 3}

By changing the interval between the movement onset and TMS, we found the timing-dependent biphasic pattern of changes in- 


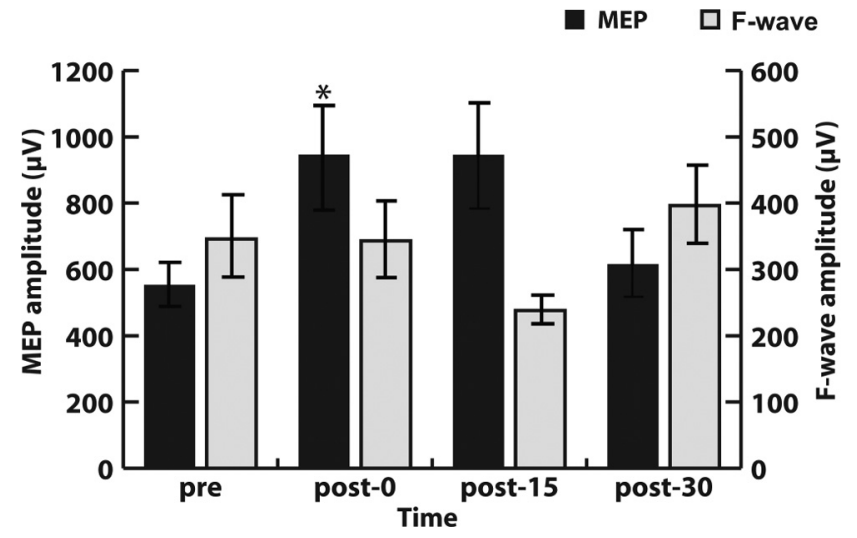

Figure 5. Effect of $\operatorname{MRCS}(-50)$ on the corticospinal and spinal excitability. The mean MEP and F-wave amplitudes measured from the right APB for pre, post -0 , post-15, and post-30 conditions are shown. Only the MEP for post- 0 condition, but not F-wave, showed significant increase.

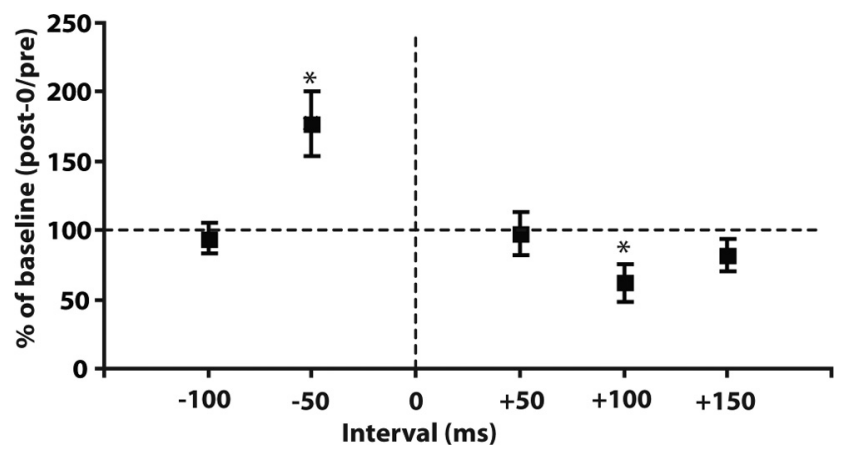

Figure 6. The mean MEP amplitude ratios (post-0/pre) recorded from the right APB as a function of intervals between TMS and the mean reaction time. Significant increase of MEP for post- 0 compared with pre was observed for MRCS $(-50)$, while significant decrease was demonstrated for $\operatorname{MRCS}(+100)$.

duced by MRCS. Since the largest change of MEP amplitudes was observed at the post- 0 condition, we performed two-way repeatedmeasures ANOVA for interaction between time (pre, post0), and ISI $(-100,-50,+50,+100,+150)$ as the within-subjects factors, which was found to be significant $(F=6.722, p=0.028$, Fig. 6). Post hoc $t$ test (pre vs post-0) revealed the significant increase for $\operatorname{MRCS}(-50)$ and decrease for $\operatorname{MRCS}(+100)(p=0.023$ and 0.036 , respectively, Fig. 6) but not for other ISIs.

\section{Discussion}

We found that rTMS of M1 paired with voluntary movement (MRCS) can induce change in the corticospinal excitability and motor behavior that outlasted the stimulation period. The characteristics of this change are similar to associative LTP/LTD in animal models; as it rapidly developed (within $20 \mathrm{~min}$ ), sustained after intervention, showed associativity (TMS associated with voluntary movement), and was input-specific (as M1 excitability changed only in right $\mathrm{APB}$ "the moving" rather than right $\mathrm{ADM}$ "the resting" muscles). Additionally, this form of induced plasticity was timing-dependent, as its direction was governed by the order of TMS and the onset of voluntary movement. Absence of F-wave change following MRCS suggests cortical origin of induced plasticity.

Many earlier studies induced human associative plasticity in the motor (Stefan et al., 2000, 2002, 2004; Ridding and Taylor, 2001; Wolters et al., 2003; Müller-Dahlhaus et al., 2008; Di
Lazzaro et al., 2009) and somatosensory (Wolters et al., 2005) cortices by pairing peripheral electrical nerve stimulation with TMS. Also, it was found that associative stimulation of motor cortices bilaterally can induce lasting excitability changes in the target M1 (Koganemaru et al., 2009; Rizzo et al., 2009).

Recent animal studies have stressed the importance of the temporal order of presynaptic and postsynaptic spiking of associative stimulation, and have defined temporal windows of tens of milliseconds for the direction of induced plasticity (Markram et al., 1997; Debanne et al., 1998; Zhang et al., 1998; Egger et al., 1999; Feldman, 2000; Sjöström et al., 2001; Froemke and Dan, 2002; Tzounopoulos et al., 2004). This form of synaptic plasticity is known as spike timing-dependent plasticity (STDP). If postsynaptic spiking occurs within a specific time window after synaptic activation, LTP is induced, whereas spiking before synaptic activation leads to LTD (Bi and Poo, 1998). This time window was found to be variable from one site to another within the brain and can be 50 ms or more (Bell et al., 1997; Markram et al., 1997; Debanne et al., 1998; Zhang et al., 1998; Egger et al., 1999; Feldman, 2000; Froemke and Dan, 2002; Tzounopoulos et al., 2004).

There are two forms of synaptic plasticity, which are homoand heterosynaptic plasticity. The homosynaptic plasticity refers to changes in the strength of a synapse due to its own activity, however the heterosynaptic plasticity, is a change in the strength of a synapse due to activity in another pathway (Kelso and Brown, 1986; Bradler and Barrioneuvo, 1989). In previous PAS studies (Stefan et al., 2000; Wolters et al., 2003, 2005) and in our MRCS study, the induced M1 plasticity may be related to homosynaptic form of LTP/LTD as the change in MEP amplitude occurred in muscles innervated by the stimulated peripheral nerve in PAS, and in the moving rather than resting muscle in MRCS. The direction of change in the M1 excitability induced by PAS and MRCS is determined by the timing rule similar to STDP (Wolters et al., 2003).

The increase of MEP amplitude in the present study was not associated with change in F-wave amplitude recorded in the same muscle, suggesting that M1 excitability change induced by MRCS occurred at the cortical rather than spinal level (Mercuri et al., 1996; Stefan et al., 2000).

Since the change of MEP was not associated with any change of rMT, the effect of MRCS may not be related to the resting membrane potential properties of the corticospinal neurons (Ziemann et al., 1996a). This finding is in agreement with other PAS and bihemispheric stimulation protocols (Stefan et al., 2000; Wolters et al., 2003; Fratello et al., 2006; Koganemaru et al., 2009; Rizzo et al., 2009).

Intracortical inhibitory system plays an important role in changing M1 excitability (Peinemann et al., 2000; Sanes and Donoghue, 2000; Di Lazzaro et al., 2002; Plewnia et al., 2003) and motor performance (Ridding et al., 1995; Garry et al., 2004; Sale and Semmler, 2005; Rosenkranz et al., 2007). Thus, we studied SICI which partly reflects GABA-A, and SP which is related to GABA-B inhibitory cortical neurons activities (Chen, 2004; Ziemann, 2004). The SICI was not changed by MRCS, suggesting that the-induced M1 plasticity is not directly related to GABA-A neuronal activity. Other PAS protocols showed similar results (Ridding and Taylor, 2001; Stefan et al., 2002; Sale et al., 2007). However, MRCS $(-50)$ significantly increased SP duration similar to other PAS protocols (Stefan et al., 2000; Sale et al., 2007; Cirillo et al., 2009).

Long-term potentiation of inhibitory synapses was observed in many brain areas (Morishita and Sastry, 1991; Kano et al., 1992; 
Komatsu and Iwakiri, 1993; Aizenman et al., 1998). The change in SP duration might reflect the MRCS-induced LTP-like effect on inhibitory synapses within M1 (Nicoll et al., 1996; Buonomano and Merzenich, 1998). Since SP duration is thought to reflect the movementrelated activity of GABA-B inhibitory circuits during voluntary contraction (Ziemann, 2004), MRCS(-50) might induce increase in synaptic strength within these circuits similar to the excitatory circuits responsible for MEP, leading to simultaneous increase in the MEP amplitude and SP duration.

MRCS(-50) significantly shortened RT in addition to MEP amplitude increase of the right APB. Previous studies showed improvement in motor behavior due to LTP-like effects in M1 induced by high-frequency rTMS (Khedr et al., 2003, 2005; Bütefisch, 2004), associative stimulations (Koganemaru et al., 2009; Rizzo et al., 2009), and anodal transcranial direct current stimulation (DCS) (Hummel and Cohen, 2005, 2006). Therefore, it is likely that shortened RT might reflect increased M1 excitability.

We found significant increase and decrease in MEP amplitude of the right $\mathrm{APB}$ muscle for $\operatorname{MRCS}(-50)$ and $\operatorname{MRCS}(+100)$. However this bidirectional change in excitability was not generalized to the right ADM muscle, which was not involved in the voluntary movement task. This finding suggests that the M1 plasticity in MRCS is governed by strict somatotopy based on muscle activity in movement task. This somatotopy is consistent with other associative plasticity protocols (Stefan et al., 2000; Wolters et al., 2003, 2005).

In human studies, the motor potential (MP) component of movement related cortical potential (MRCP), synonymously called initial slope motor potential (isMP) (Tarkka and Hallett, 1991) and N-10 potential (Shibasaki et al., 1980), occurs partly before and after the EMG onset. This potential probably represents activation of pyramidal tract neurons in $\mathrm{M} 1$, and persists for 30-50 ms after the onset of EMG activity (Hallett, 1994; Shibasaki and Hallett, 2006). If we applied the STDP rule induced in animals to our protocol, we may find an explanation to our results as; TMS pulse will precede/follow the activation of M1 neurons which are somatotopically related (as discussed before) to movement execution in $\operatorname{MRCS}(-50)$ and $\operatorname{MRCS}(+100)$ leading to increase/decrease of synaptic strength within those neuronal circuits.

Animal studies have shown that M1 directly and indirectly receives multiple inputs from other cortical and subcortical regions that may play important roles in motor processing, including premotor, supplementary motor, cingulated motor, somatosensory and prefrontal cortex, and anterior thalamic nuclei which indirectly connect cerebellum and basal ganglia outputs to M1(Strick, 1985; Orioli and Strick, 1989; Hoover and Strick, 1993; Stepniewska et al., 1993; Kaneko et al., 1994; Lu et al., 1994; Farkas et al., 1999). During movement execution, top-down synchronous firing of pyramidal neurons (Weiler et al., 2008) occurs in all layers (including layers $2 / 3$ and 5) of M1 (Isomura et al., 2009). The activity of those neurons stops at the end of movement execution and replaced by activation of other neuronal subsets in layers 4 and 6 during movement-off and post-movement phases of motor action (Maiorov, 2003; Isomura et al., 2009).

In conclusion, this study provides a new associative stimulation TMS protocol that can be used for induction of M1 plasticity. In previous protocols, peripheral electrical stimulation and contralateral M1 conditioning TMS were used (Stefan et al., 2000, 2002; Wolters et al., 2003; Koganemaru et al., 2009; Rizzo et al., 2009) to induce M1 plasticity. However in our MRCS, intrinsic M1 activation was used. Our study may provide the evidence that associative stimulation-induced plasticity is a rather general principle independent of the nature of used stimuli. The finding that MRCS may induce M1 plasticity supports the possibility of its use for rehabilitation of neurological disability after vascular (Hummel and Cohen, 2005; Khedr et al., 2005; Fregni et al., 2006; Kim et al., 2006), inflammatory (Centonze et al., 2007a,b; Koch et al., 2008) or degenerative brain diseases (Khedr et al., 2003, 2006; Lomarev et al., 2006). Since topographical specificity is an important characteristic of MRCS-induced plasticity, it can be used to induce movement-specific M1 plasticity, rather than generalized increase/decrease of M1 plasticity induced by rTMS (Chen et al., 1997; Wu et al., 2000; Gilio et al., 2003; Quartarone et al., 2005) or DCS (Nitsche and Paulus, 2000, 2001; Nitsche et al., 2003), which can be tailored to match different rehabilitation situations.

\section{References}

Aizenman CD, Manis PB, Linden DJ (1998) Polarity of long-term synaptic gain change is related to postsynaptic spike firing at a cerebellar inhibitory synapse. Neuron 21:827-835.

Allen GI, Tsukahara N (1974) Cerebrocerebellar communication systems. Physiol Rev 54:957-1006.

Bell CC, Han VZ, Sugawara Y, Grant K (1997) Synaptic plasticity in a cerebellum-like structure depends on temporal order. Nature 387:278-281.

Bi GQ, Poo MM (1998) Synaptic modifications in cultured hippocampal neurons: dependence on spike timing, synaptic strength, and postsynaptic cell type. J Neurosci 18:10464-10472.

Bliss TV, Lomo T (1973) Long-lasting potentiation of synaptic transmission in the dentate area of the anaesthetized rabbit following stimulation of the perforant path. J Physiol 232:331-356.

Bradler JE, Barrioneuvo G (1989) Long-term potentiation in hippocampal CA3 neurons: tetanized input regulates heterosynaptic efficacy. Synapse 4:132-142.

Buonomano DV, Merzenich MM (1998) Cortical plasticity: from synapses to maps. Annu Rev Neurosci 21:149-186.

Bütefisch CM (2004) Plasticity in the human cerebral cortex: lessons from the normal brain and from stroke. Neuroscientist 10:163-173.

Centonze D, Petta F, Versace V, Rossi S, Torelli F, Prosperetti C, Rossi S, Marfia GA, Bernardi G, Koch G, Miano R, Boffa L, Finazzi-Agrò E (2007a) Effects of motor cortex rTMS on lower urinary tract dysfunction in multiple sclerosis. Mult Scler 13:269-271.

Centonze D, Koch G, Versace V, Mori F, Rossi S, Brusa L, Grossi K, Torelli F, Prosperetti C, Cervellino A, Marfia GA, Stanzione P, Marciani MG, Boffa L, Bernardi G (2007b) Repetitive transcranial magnetic stimulation of the motor cortex ameliorates spasticity in multiple sclerosis. Neurology 68:1045-1050.

Chen R (2004) Interactions between inhibitory and excitatory circuits in the human motor cortex. Exp Brain Res 154:1-10.

Chen R, Classen J, Gerloff C, Celnik P, Wassermann EM, Hallett M, Cohen LG (1997) Depression of motor cortex excitability by low-frequency transcranial magnetic stimulation. Neurology 48:1398-1403.

Cirillo J, Lavender AP, Ridding MC, Semmler JG (2009) Motor cortex plasticity induced by paired associative stimulation is enhanced in physically active individuals. J Physiol 587:5831-5842.

Citri A, Malenka RC (2008) Synaptic plasticity: multiple forms, functions, and mechanisms. Neuropsychopharmacology 33:18-41.

Debanne D, Gähwiler BH, Thompson SM (1998) Long-term synaptic plasticity between pairs of individual CA3 pyramidal cells in rat hippocampal slice cultures. J Physiol 507:237-247.

Di Lazzaro V, Oliviero A, Mazzone P, Pilato F, Saturno E, Dileone M, Insola A, Tonali PA, Rothwell JC (2002) Short-term reduction of intracortical inhibition in the human motor cortex induced by repetitive transcranial magnetic stimulation. Exp Brain Res 147:108-113.

Di Lazzaro V, Dileone M, Pilato F, Profice P, Oliviero A, Mazzone P, Insola A, Capone F, Ranieri F, Tonali PA (2009) Associative motor cortex plasticity: direct evidence in humans. Cereb Cortex 19:2326-2330.

Egger V, Feldmeyer D, Sakmann B (1999) Coincidence detection and changes of synaptic efficacy in spiny stellate neurons in rat barrel cortex. Nat Neurosci 2:1098-1105.

Farkas T, Kis Z, Toldi J, Wolff JR (1999) Activation of the primary motor cortex by somatosensory stimulation in adult rats is mediated mainly by 
associational connections from the somatosensory cortex. Neuroscience 90:353-361.

Feldman DE (2000) Timing-based LTP and LTD at vertical inputs to layer II/III pyramidal cells in rat barrel cortex. Neuron 27:45-56.

Fratello F, Veniero D, Curcio G, Ferrara M, Marzano C, Moroni F, Pellicciari MC, Bertini M, Rossini PM, De Gennaro L (2006) Modulation of corticospinal excitability by paired associative stimulation: reproducibility of effects and intraindividual reliability. Clin Neurophysiol 117:2667-2674.

Fregni F, Boggio PS, Valle AC, Rocha RR, Duarte J, Ferreira MJ, Wagner T, Fecteau S, Rigonatti SP, Riberto M, Freedman SD, Pascual-Leone A (2006) A sham-controlled trial of a 5-day course of repetitive transcranial magnetic stimulation of the unaffected hemisphere in stroke patients. Stroke 37:2115-2122.

Froemke RC, Dan Y (2002) Spike-timing-dependent synaptic modification induced by natural spike trains. Nature 416:433-438.

Garry MI, Kamen G, Nordstrom MA (2004) Hemispheric differences in the relationship between corticomotor excitability changes following a finemotor task and motor learning. J Neurophysiol 91:1570-1578.

Gilio F, Rizzo V, Siebner HR, Rothwell JC (2003) Effects on the right motor hand-area excitability produced by low-frequency rTMS over human contralateral homologous cortex. J Physiol 551:563-573.

Hallett M (1994) Movement-related cortical potentials. Electromyogr Clin Neurophysiol 34:5-13.

Hebb D (1949) The organization of behaviour; a neuropsychological theory. New York: Wiley.

Hoover JE, Strick PL (1993) Multiple output channels in the basal ganglia. Science 259:819-821.

Hummel F, Cohen LG (2005) Improvement of motor function with noninvasive cortical stimulation in a patient with chronic stroke. Neurorehabil Neural Repair 19:14-19.

Hummel FC, Cohen LG (2006) Non-invasive brain stimulation: a new strategy to improve neurorehabilitation after stroke? Lancet Neurol 5:708-712.

Isomura Y, Harukuni R, Takekawa T, Aizawa H, Fukai T (2009) Microcircuitry coordination of cortical motor information in self-initiation of voluntary movements. Nat Neurosci 12:1586-1593.

Jackson A, Mavoori J, Fetz EE (2006) Long-term motor cortex plasticity induced by an electronic neural implant. Nature 444:56-60.

Kaneko T, Caria MA, Asanuma H (1994) Information processing within the motor cortex. II. Intracortical connections between neurons receiving somatosensory cortical input and motor output neurons of the cortex. J Comp Neurol 345:172-184.

Kano M, Rexhausen U, Dreessen J, Konnerth A (1992) Synaptic excitation produces a long-lasting rebound potentiation of inhibitory synaptic signals in cerebellar Purkinje cells. Nature 356:601-604.

Kelso SR, Brown TH (1986) Differential conditioning of associative synaptic enhancement in hippocampal brain slices. Science 232:85-87.

Khedr EM, Farweez HM, Islam H (2003) Therapeutic effect of repetitive transcranial magnetic stimulation on motor function in Parkinson's disease patients. Eur J Neurol 10:567-572.

Khedr EM, Ahmed MA, Fathy N, Rothwell JC (2005) Therapeutic trial of repetitive transcranial magnetic stimulation after acute ischemic stroke. Neurology 65:466-468.

Khedr EM, Rothwell JC, Shawky OA, Ahmed MA, Hamdy A (2006) Effect of daily repetitive transcranial magnetic stimulation on motor performance in Parkinson's disease. Mov Disord 21:2201-2205.

Kim YH, You SH, Ko MH, Park JW, Lee KH, Jang SH, Yoo WK, Hallett M (2006) Repetitive transcranial magnetic stimulation-induced corticomotor excitability and associated motor skill acquisition in chronic stroke. Stroke 37:1471-1476.

Koch G, Rossi S, Prosperetti C, Codecà C, Monteleone F, Petrosini L, Bernardi G, Centonze D (2008) Improvement of hand dexterity following motor cortex rTMS in multiple sclerosis patients with cerebellar impairment. Mult Scler 14:995-998.

Koganemaru S, Mima T, Nakatsuka M, Ueki Y, Fukuyama H, Domen K (2009) Human motor associative plasticity induced by paired bihemispheric stimulation. J Physiol 587:4629-4644.

Komatsu Y, Iwakiri M (1993) Long-term modification of inhibitory synaptic transmission in developing visual cortex. Neuroreport 4:907-910.

Kujirai T, Caramia MD, Rothwell JC, Day BL, Thompson PD, Ferbert A, Wroe S, Asselman P, Marsden CD (1993) Corticocortical inhibition in human motor cortex. J Physiol 471:501-519.
Lomarev MP, Kanchana S, Bara-Jimenez W, Iyer M, Wassermann EM, Hallett M (2006) Placebo-controlled study of rTMS for the treatment of Parkinson's disease. Mov Disord 21:325-331.

Lu MT, Preston JB, Strick PL (1994) Interconnections between the prefrontal cortex and the premotor areas in the frontal lobe. J Comp Neurol 341:375-392.

Maiorov VI (2003) A computer model of neural processes observed in the cat motor cortex during performance of an operant movement. Neurosci Behav Physiol 33:567-578.

Markram H, Lübke J, Frotscher M, Sakmann B (1997) Regulation of synaptic efficacy by coincidence of postsynaptic APs and EPSPs. Science 275 213-215.

Martin SJ, Grimwood PD, Morris RG (2000) Synaptic plasticity and memory: an evaluation of the hypothesis. Annu Rev Neurosci 23:649-711.

Mercuri B, Wassermann EM, Manganotti P, Ikoma K, Samii A, Hallett M (1996) Cortical modulation of spinal excitability: an F-wave study. Electroencephalogr Clin Neurophysiol 101:16-24.

Morishita W, Sastry BR (1991) Chelation of postsynaptic Ca2+ facilitates long-term potentiation of hippocampal IPSPs. Neuroreport 2:533-536.

Müller-Dahlhaus JF, Orekhov Y, Liu Y, Ziemann U (2008) Interindividual variability and age-dependency of motor cortical plasticity induced by paired associative stimulation. Exp Brain Res 187:467-475.

Nicoll A, Kim HG, Connors BW (1996) Laminar origins of inhibitory synaptic inputs to pyramidal neurons of the rat neocortex. J Physiol 497:109-117.

Nitsche MA, Paulus W (2000) Excitability changes induced in the human motor cortex by weak transcranial direct current stimulation. J Physiol 527:633-639.

Nitsche MA, Paulus W (2001) Sustained excitability elevations induced by transcranial DC motor cortex stimulation in humans. Neurology 57: 1899-1901.

Nitsche MA, Nitsche MS, Klein CC, Tergau F, Rothwell JC, Paulus W (2003) Level of action of cathodal DC polarisation induced inhibition of the human motor cortex. Clin Neurophysiol 114:600-604.

Oldfield RC (1971) The assessment and analysis of handedness: the Edinburgh inventory. Neuropsychologia 9:97-113.

Orioli PJ, Strick PL (1989) Cerebellar connections with the motor cortex and the arcuate premotor area: an analysis employing retrograde transneuronal transport of WGA-HRP. J Comp Neurol 288:612-626.

Peinemann A, Lehner C, Mentschel C, Münchau A, Conrad B, Siebner HR (2000) Subthreshold $5 \mathrm{~Hz}$ repetitive transcranial magnetic stimulation of the human primary motor cortex reduces intracortical paired-pulse inhibition. Neurosci Lett 296:21-24.

Plewnia C, Lotze M, Gerloff C (2003) Disinhibition of the contralateral motor cortex by low-frequency rTMS. Neuroreport 14:609-612.

Quartarone A, Bagnato S, Rizzo V, Morgante F, Sant'angelo A, Battaglia F, Messina C, Siebner HR, Girlanda P (2005) Distinct changes in cortical and spinal excitability following high-frequency repetitive TMS to the human motor cortex. Exp Brain Res 161:114-124.

Ridding MC, Taylor JL (2001) Mechanisms of motor-evoked potential facilitation following prolonged dual peripheral and central stimulation in humans. J Physiol 537:623-631.

Ridding MC, Sheean G, Rothwell JC, Inzelberg R, Kujirai T (1995) Changes in the balance between motor cortical excitation and inhibition in focal, task specific dystonia. J Neurol Neurosurg Psychiatry 59:493-498.

Rizzo V, Siebner HS, Morgante F, Mastroeni C, Girlanda P, Quartarone A (2009) Paired associative stimulation of left and right human motor cortex shapes interhemispheric motor inhibition based on a Hebbian mechanism. Cereb Cortex 19:907-915.

Rosenkranz K, Williamon A, Rothwell JC (2007) Motorcortical excitability and synaptic plasticity is enhanced in professional musicians. J Neurosci 27:5200-5206.

Rossini PM, Barker AT, Berardelli A, Caramia MD, Caruso G, Cracco RQ, Dimitrijevic MR, Hallett M, Katayama Y, Lücking CH, Maertens de Noordhout AL, Marsden CD, Murray NMF, Rothwell JC, Swash M, Tomberg C (1994) Non-invasive electrical and magnetic stimulation of the brain, spinal cord and roots: basic principles and procedures for routine clinical application. Report of an IFCN committee. Electroencephalogr Clin Neurophysiol 91:79-92.

Rothwell JC, Hallett M, Berardelli A, Eisen A, Rossini P, Paulus W (1999) 
Magnetic stimulation: motor evoked potentials. The International Federation of Clinical Neurophysiology. Electroencephalogr Clin Neurophysiol Suppl 52:97-103.

Sale MV, Semmler JG (2005) Age-related differences in corticospinal control during functional isometric contractions in left and right hands. J Appl Physiol 99:1483-1493.

Sale MV, Ridding MC, Nordstrom MA (2007) Factors influencing the magnitude and reproducibility of corticomotor excitability changes induced by paired associative stimulation. Exp Brain Res 181:615-626.

Sanes JN, Donoghue JP (2000) Plasticity and primary motor cortex. Annu Rev Neurosci 23:393-415.

Shibasaki H, Hallett M (2006) What is the Bereitschaftspotential? Clin Neurophysiol 117:2341-2356.

Shibasaki H, Barrett G, Halliday E, Halliday AM (1980) Components of the movement-related cortical potential and their scalp topography. Electroencephalogr Clin Neurophysiol 49:213-226.

Sjöström PJ, Turrigiano GG, Nelson SB (2001) Rate, timing, and cooperativity jointly determine cortical synaptic plasticity. Neuron 32:1149-1164.

Stefan K, Kunesch E, Cohen LG, Benecke R, Classen J (2000) Induction of plasticity in the human motor cortex by paired associative stimulation. Brain 123:572-584

Stefan K, Kunesch E, Benecke R, Cohen LG, Classen J (2002) Mechanisms of enhancement of human motor cortex excitability induced by interventional paired associative stimulation. J Physiol 543:699-708.

Stefan K, Wycislo M, Classen J (2004) Modulation of associative human motor cortical plasticity by attention. J Neurophysiol 92:66-72.

Stepniewska I, Preuss TM, Kaas JH (1993) Architectionis, somatotopic organization, and ipsilateral cortical connections of the primary motor area (M1) of owl monkeys. J Comp Neurol 330:238-271.
Strick PL (1985) How do the basal ganglia and cerebellum gain access to the cortical motor areas? Behav Brain Res 18:107-123.

Tarkka IM, Hallett M (1991) Topography of scalp-recorded motor potentials in human finger movements. J Clin Neurophysiol 8:331-341.

Tzounopoulos T, Kim Y, Oertel D, Trussell LO (2004) Cell-specific, spike timing-dependent plasticities in the dorsal cochlear nucleus. Nat Neurosci 7:719-725.

Weiler N, Wood L, Yu J, Solla SA, Shepherd GM (2008) Top-down laminar organization of the excitatory network in motor cortex. Nat Neurosci 11:360-366.

Wolters A, Sandbrink F, Schlottmann A, Kunesch E, Stefan K, Cohen LG, Benecke R, Classen J (2003) A temporally asymmetric Hebbian rule governing plasticity in the human motor cortex. J Neurophysiol 89: 2339-2345.

Wolters A, Schmidt A, Schramm A, Zeller D, Naumann M, Kunesch E, Benecke R, Reiners K, Classen J (2005) Timing-dependent plasticity in human primary somatosensory cortex. J Physiol 565:1039-1052.

Wu T, Sommer M, Tergau F, Paulus W (2000) Lasting influence of repetitive transcranial magnetic stimulation on intracortical excitability in human subjects. Neurosci Lett 287:37-40.

Zhang LI, Tao HW, Holt CE, Harris WA, Poo M (1998) A critical window for cooperation and competition among developing retinotectal synapses. Nature 395:37-44.

Ziemann U (2004) TMS and drugs. Clin Neurophysiol 115:1717-1729.

Ziemann U, Lönnecker S, Steinhoff BJ, Paulus W (1996a) Effects of antiepileptic drugs on motor cortex excitability in humans: a transcranial magnetic stimulation study. Ann Neurol 40:367-378.

Ziemann U, Rothwell JC, Ridding MC (1996b) Interaction between intracortical inhibition and facilitation in human motor cortex. J Physiol 496 873-881. 